\title{
DIREITO À ALIMENTAÇÃO: DIREITO, CONSUMO, POLÍTICA E ÉTICA NO BRASIL
}

\author{
RIGHT TO FOOD: LAW, CONSUPTION, POLITICS AND ETHICS IN BRAZIL
}

\section{DERECHO A LA ALIMENTACIÓN: DERECHO, CONSUMO, POLÍTICA Y ÉTICA EN BRASIL}

\section{Daniela Rosendo ${ }^{1}$}

\section{Tânia Aparecida Kuhnen²}

Licença CC BY:

Artigo distribuído sob os termos Creative Commons, permite uso e distribuição irrestrita em qualquer meio desde que o autor credite a fonte original.

\section{(c) (i)}

Resumo: $O$ artigo aborda o direito humano à alimentação adequada previsto na Constituição Federal e especifica como se constitui a "alimentação adequada" à luz das dimensões ética e política que a permeiam. O objetivo geral é investigar o direito humano à alimentação adequada e às limitações de seu conceito legal, repensado a partir de considerações com origem na reflexão política e ética. A metodologia adotada envolve a pesquisa bibliográfica e documental, de caráter exploratório. Com base na discussão apresentada sobre o conceito de alimentação adequada, conclui-se que, para além de erradicar a fome, o direito à alimentação deve ser entendido de maneira mais ampla, de modo a pensar também no modo de produção dos alimentos e seus impactos tanto para os humanos quanto para os demais animais sencientes, passando necessariamente por uma reflexão do próprio consumidor, que deve ter acesso à informação, a fim de realizar escolhas conscientes.

Palavras-chave: Direito humano à alimentação adequada. Guia Popular para a Alimentação Brasileira. Consumidor verde. Sustentabilidade socioambiental. Senciência.

Abstract:The article addresses the human right to adequate food provided for in the Federal Constitution, and specifies how "adequate food" is constituted in light of the ethical and political dimensions that permeate it. The main aim is to investigate the human right to adequate food and the limitations of its legal concept, rethought from considerations originating in political and ethical reflection. The methodology adopted involves bibliographic and documentary research of an exploratory nature. Based on the discussion on the concept of adequate food, it is concluded that

$1 \quad$ Doutoranda e mestra em Filosofia, na área de Ética e Filosofia Política, pela Universidade Federal de Santa Catarina (UFSC), e Bacharel em Direito pela Universidade da Região de Joinville (UNIVILLE). É professora da Associação Catarinense de Ensino/Faculdade Guilherme Guimbala (ACE/FGG), em Joinville/Santa Catarina/ Brasil, e integrante do Comitê Latino Americano e do Caribe para a Defesa dos Direitos da Mulher (CLADEM Brasil). E-mail: daniela.rosendo84@gmail.com

2 Doutora, mestra e graduada em Filosofia pela Universidade Federal de Santa Catarina (UFSC). Professora Adjunta na Universidade Federal do Oeste da Bahia (UFOB), em Barreiras/Bahia/Brasil, onde integra o corpo docente do Programa de Pós-Graduação em Ciências Humanas e Sociais (PPGCHS). É membro dos grupos de pesquisa Corpus Possíveis: Educação, Cultura e Diferenças e Gestão, Inovação e Desenvolvimento, ambos vinculados à UFOB, além de colaborar com o Laboratório de Ética Ambiental e Animal (LEA-UFF) e o Grupo IPÊS (FURB). E-mail: tania.kuhnen@ufob.edu.br 
in addition to eradicating hunger, the right to food must be understood in a broader sense, thinking about the way food is produced and its impacts both for humans and other sentient animals. This must include reflection by the consumer, who must have access to information in order to make conscious choices.

Key-words: Human Right to adequate food. Popular Guide to Brazilian Food. Green consumer. Socio-environmental sustainability. Sentience.

Resumen: El artículo aborda el derecho humano a la alimentación adecuada previsto en la Constitución Federal y específica, como se constituye la "alimentación adecuada" a la luz de las dimensiones ética y política que la permean. El objetivo general es investigar el derecho humano a la alimentación adecuada y a las limitaciones de su concepto legal, repensado a partir de consideraciones con origen en la reflexión política y ética. La metodología adoptada envuelve la investigación bibliográfica y documental, de carácter exploratorio. Con base en la discusión presentada sobre el concepto de alimentación adecuada, se concluye que, para además de erradicar el hambre, el derecho a la alimentación debe ser entendido de manera más amplia, de modo a pensar también en el modo de producción de los alimentos y sus impactos tanto para los humanos como para los demás animales sencientes, pasando necesariamente por una reflexión del propio consumidor, que debe tener acceso a la información, a fin de realizar elecciones conscientes.

Palabras - clave: Derecho humano a la alimentación adecuada. Guía Popular para la Alimentación Brasileña. Consumidor verde. Sustentabilidad socioambiental. Senciencia.

\section{INTRODUÇÃO}

O presente artigo busca discutir a noção de alimentação "adequada", proposta no Brasil por meio da Lei $n^{\circ} 11.346$, de 15 de setembro de 2006, que deu expressão prática ao direito fundamental de cada ser humano de acesso à alimentação. Vinculada, então, ao direito social constitucional à alimentação, a ideia do que constitui uma alimentação adequada, embora proposta na lei, permanece em aberto. Uma dimensão positiva a essa noção de alimentação foi recentemente reconhecida por meio da edição do Guia Popular para a Alimentação Brasileira (2014), o qual se coloca como um instrumento de resgate e preservação da variedade alimentar e nutricional vinculada às diferenças culturais regionais da população brasileira, sobrepondo-se ao modelo de colonização e uniformização alimentar que ganha espaço em meio às formas contemporâneas de vida.

Importa destacar que o objetivo aqui não é justificar um dever de garantir alimentação aos sujeitos que, comumente em situação de pobreza, não se encontram em condições financeiras de prouverem a si mesmos e a seus familiares 
com a alimentação necessária. Esse direito está reconhecido na Constituição Federal de 1988, no sentido de garantir que necessidades básicas e mínimas para a dignidade humana estejam asseguradas. O problema central que permeia a presente discussão é especificar o que seria uma alimentação adequada, noção que é introduzida pela Lei $n^{\circ} 11.346 / 2006$. Para tratar dessa questão, parte-se da hipótese de que a alimentação adequada é um conceito complexo cujo sentido se expande para além de uma abordagem jurídica e envolve elementos éticos, políticos e sociais. O objetivo geral consiste, portanto, em investigar o direito humano à alimentação adequada e as limitações de seu conceito legal, a ser repensado à luz das dimensões ética e política da alimentação. Dessa forma, ao longo do texto, busca-se vincular a proposta legal ao debate político e ético, com o fim de melhor especificar a noção de alimentação adequada. Tanto a dimensão política do ato de alimentar-se, isto é, um ato que não ocorre de forma isolada, mas se dá em meio a uma cadeia de relações sociais, econômicas e produtivas, quanto a noção do bem-estar individual de seres sencientes analisada do ponto de vista da ética podem contribuir para melhor definir no que consiste a alimentação adequada. Para tanto, é importante também pensar a alimentação como associada a uma concepção de saúde.

Justifica-se a realização desta pesquisa em razão da importância de se refletir sobre a complexidade que atravessa o direito humano fundamental à alimentação adequada, à medida em que se consideram a diversidade das práticas alimentares humanas, a falta de acesso a uma variedade adequada de alimentos de parte significativa da população, bem como as recentes contribuições teóricas no âmbito da ética animal e ambiental que têm resultado em uma problematização moral das escolhas alimentares humanas. Diante dessa complexidade, salientese ainda o caráter interdisciplinar da investigação aqui desenvolvida à medida que se integram contribuições do campo jurídico e filosófico. O tema abordado de forma interdisciplinar conta com contribuições do Direito Constitucional e do Direito Ambiental para discutir criticamente a ideia de sustentabilidade, permeada por apontamentos teóricos do campo da Ética e da Política.

A metodologia adotada neste estudo parte da pesquisa bibliográfica e documental, de caráter exploratório. No que tange à pesquisa bibliográfica, 
busca-se em autores, sobretudo do Direito, o conceito do direito humano à alimentação adequada e em autores da Ética Contemporânea as contribuições para aprofundar a reflexão crítica sobre esse mesmo conceito. A pesquisa documental parte da análise da legislação que estabelece o direito à alimentação adequada, além do se considerar documentos da ONU, FAO e o Guia Alimentar da População Brasileira para trazer à tona os aspectos políticos e éticos envolvidos no conceito de alimentação adequada. Trata-se de uma pesquisa exploratória em razão de se procurar aprofundar o debate sobre a noção de alimentação adequada para além da compreensão legal do conceito, contribuindo-se de modo a "desenvolver, esclarecer e modificar conceitos e ideias" ampliar e aprofundar o entendimento do que integra uma alimentação adequada.

\section{DIREITO HUMANO À ALIMENTAÇÃO ADEQUADA (DHAA)}

O reconhecimento da alimentação como um direito passa, necessariamente, pela discussão sobre a erradicação da fome, um problema social e político de ordem mundial que se constitui como objeto de debate sobretudo na área sociológica. Segundo dados da Organização das Nações Unidas para Alimentação e Agricultura (FAO), embora tenha havido uma redução na fome mundial, estima-se que havia cerca de 805 milhões de pessoas com subnutrição crônica no período entre 2012 e 2014. ${ }^{4}$ Contudo, ao contrário do que se tenta mascarar, a fome não é decorrente de uma suposta falta de alimentos, nem da fatalidade, sendo que as justificativas "naturalistas" para o problema, relacionadas comumente a fatores climáticos, não são suficientes para explicar esse problema. ${ }^{5}$ Nesse sentido, dispõe o Comentário Geral $n^{\circ} 12$, do Comitê de Direitos Econômicos, Sociais e Culturais, da ONU (Comitê DESC):

Fundamentalmente, as raízes do problema da fome e desnutrição não residem na falta de alimento, mas na falta de acesso ao alimento disponível, entre outras razões por causa da pobreza de grandes segmentos da população mundial. ${ }^{6}$

3 GIL, Antônio Carlos. Métodos e técnicas de pesquisa social. 5. ed. São Paulo: Atlas, 2007.

4 FAO, IFAD and WFP. The State of Food Insecurity in the World 2014. Strengthening the enabling environment for food security and nutrition. Rome, FAO, 2014.

5 ZIEGLER, Jean. Prefácio. In: PIOVESAN, Flávia; CONTI, Irio Luiz (Coord.). Direito Humano à Alimentação Adequada. Rio de Janeiro: Lumen Juris, 2007, p. ix.

6 COMITÊ DESC. Comentário Geral $\mathbf{n}^{\circ}$ 12. Disponível em: <http://pfdc.pgr.mpf.mp.br/atuacao-e-conteudos-deapoio/publicacoes/alimentacao-adequada/Comentario\%20Geral\%20No\%2012 .pdf> Acesso em: 20 abr. 2015. 
A questão da fome, portanto, aponta para um problema social e político oriundo da pobreza e da miséria decorrentes também da falta de acesso à terra e à renda, ambos necessários para obtenção dos alimentos. ${ }^{7}$ Essas diferentes perspectivas, focadas inicialmente na produção e na oferta e depois no acesso, refletem nas diferentes noções de segurança alimentar e nutricional (SAN), como será visto adiante.

Irio Luiz Conti filia-se a Josué de Castro para mostrar o caráter econômicosocial da fome no contexto brasileiro desde a chegada de imigrantes europeus no século XIX, atraídos pela promessa de sair da pobreza e de melhores condições na vida. Contudo, "os padrões nutritivos da alimentação brasileira apresentavam qualidade e hábitos alimentares defeituosos e precários nas diferentes regiões do país, desde discretos índices de subnutrição até regiões com fome crônica."8 Associado a isso, o modelo econômico de agricultura que privilegiou a monocultura destinada à exportação, em detrimento da agricultura de subsistência, focando em algumas regiões, corroborou com a manutenção do latifúndio improdutivo, da plantação escravocrata, do analfabetismo, da pobreza e da fome. ${ }^{9}$

Segundo relatório da FAO, o Brasil alcançou a meta dos Objetivos de Desenvolvimento do Milênio (ODM), reduzindo a fome e a pobreza extrema, especialmente por meio do Programa Fome Zero, por meio do qual a SAN, e a inclusão social, associadas a políticas macroeconômicas, sociais e de agricultura, tornaram-se centrais para as políticas de governo. ${ }^{10}$

Contudo, o mesmo caminho não foi percorrido em direção à reforma agrária, esbarrando no direito de propriedade e impedindo o desenvolvimento da agricultura de subsistência e da soberania alimentar, reivindicada desde a década de 1990 pelos movimentos sociais que se posicionam contra as políticas agrícolas neoliberais associadas à Organização Mundial do Comércio e ao Banco Mundial. De acordo com os movimentos associados à Via Campesina, a qual articula as organizações camponesas da Ásia, da América, da África e da

7 CONTI, Irio Luiz. Introdução. In: PIOVESAN, Flávia; CONTI, Irio Luiz (Coord.). Direito Humano à Alimentação Adequada. Rio de Janeiro: Lumen Juris, 2007, p. 1-2.

8 CONTI, Irio Luiz. Introdução, p. 4.

9 CONTI, Irio Luiz. Introdução, p. 5.

10 FAO, IFAD and WFP. The State of Food Insecurity in the World 2014. Strengthening the enabling environment for food security and nutrition, p. 23. 
Europa, essas políticas são responsáveis pelo aumento da concentração de terra e renda, as quais dificultam a efetivação da reforma agrária e de outros serviços públicos, tal qual o saneamento básico. ${ }^{11}$

Como alternativa, a Via Campesina defende a soberania alimentar, pela qual se garante aos povos a autonomia para definir seu modo sustentável de produção, distribuição e consumo de alimentos, garantindo-os a toda a população, respeitando também os aspectos culturais. Ao associar a soberania alimentar com a segurança alimentar, garante-se a "autonomia de um povo e a defesa de modelos de produção, comércio e consumo de alimentos que sejam justos e compatíveis com os direitos fundamentais dos povos de uma nação"12.

A partir dessa contextualização histórica e política, é preciso compreender a evolução do conceito de SAN, o qual surge ao final da Primeira Guerra Mundial e é enfatizado após a Segunda, em 1945, em virtude da escassez de alimentos, antes mesmo de se falar em um direito humano à alimentação. A noção, inicialmente, restringe-se à segurança alimentar, associada à (in)suficiência de alimentos. Em decorrência da insegurança gerada pela ameaça da insuficiência, a Revolução Verde, na década de 1970, é apresentada como solução e gera grande impacto na produção de alimentos. A utilização de insumos químicos agrícolas, a substituição da semente crioula por sementes de Variedades de Alto Rendimento (VAR) e a industrialização dos alimentos acarretaram consequências ambientais, econômicas e sociais, sem que tivessem reduzido a fome, seu objetivo primordial. ${ }^{13}$

Essa primeira definição, associada ao armazenamento estratégico e à oferta de alimento, com foco no produto e não no sujeito titular de um direito à alimentação, contribuiu com o aumento de pessoas afetadas pela fome e aumentou a exclusão social. Essa noção cedeu lugar, então, à garantia do acesso físico, econômico, permanente e suficiente de alimentos para todos. Assim, no final da década de 1980 e início de 1990, agrega-se o aspecto nutricional e sanitário, passando a ser utilizada a terminologia Segurança Alimentar e Nutricional. Contudo, mesmo o conceito de SAN passa por diferentes momentos,

11 VALENTE, Flavio et al. Curso Formação em Direito Humano à Alimentação Adequada. Módulo 7. ABRANDH, 2007, p. 8.

12 VALENTE, Flavio et al. Curso Formação em Direito Humano à Alimentação Adequada. Módulo 7, p. 9.

13 VALENTE, Flavio et al. Curso Formação em Direito Humano à Alimentação Adequada. Módulo 1, p. 3-4. 
o qual surge com a I Conferência Nacional de Alimentação e Nutrição, em 1986, e é consolidado na I Conferência Nacional de Segurança Alimentar em 1994.14 Atualmente, é a Lei no 11.346, de 15 de setembro de 2006, conhecida como Lei Orgânica de Segurança Alimentar e Nutricional (LOSAN), que conceitua:

Art. 3 A segurança alimentar e nutricional consiste na realização do direito de todos ao acesso regular e permanente a alimentos de qualidade, em quantidade suficiente, sem comprometer o acesso a outras necessidades essenciais, tendo como base práticas alimentares promotoras de saúde que respeitem a diversidade cultural e que sejam ambiental, cultural, econômica e socialmente sustentáveis. ${ }^{15}$

Dessa definição, apreende-se que a SAN possui duas dimensões: a) alimentar, associada à produção, à comercialização e ao acesso ao alimento, ou seja, aos processos de disponibilidade; e b) nutricional, relacionada à escolha, ao preparo e ao consumo dos alimentos, envolvendo a saúde. ${ }^{16}$ Além disso, o artigo $4^{\circ}$ da LOSAN dispõe sobre alguns aspectos que também envolvem a SAN, como segurança, qualidade e sustentabilidade do alimento, bem como do acesso à informação. ${ }^{17}$

Foi a partir dessa concepção de SAN que surgiu, na década de 1990, a preocupação com um Direito Humano à Alimentação Adequada (DHAA), que também possui duas dimensões: a) direito de estar livre da fome e da má nutrição; e b) direito à alimentação adequada. Além disso, quatro aspectos são incorporados

14 VALENTE, Flavio et al. Curso Formação em Direito Humano à Alimentação Adequada. Módulo 1, p. 5.

15 BRASIL. Lei $\mathbf{n}^{\circ} \mathbf{1 1 . 3 4 6}$, de 15 de setembro de 2006. Cria o Sistema Nacional de Segurança Alimentar e Nutricional - SISAN com vistas em assegurar o direito humano à alimentação adequada e dá outras providências. Disponível em: <http://www.planalto.gov.br/ccivil_03/_ato2004- 2006/2006/lei//11346.htm> Acesso em: 31 jul. 2015.

16 VALENTE, Flavio et al. Curso Formação em Direito Humano à Alimentação Adequada. Módulo 1, p. 5.

17 "Art. 4ㅇ $\mathrm{A}$ segurança alimentar e nutricional abrange:

I - a ampliação das condições de acesso aos alimentos por meio da produção, em especial da agricultura tradicional e familiar, do processamento, da industrialização, da comercialização, incluindo-se os acordos internacionais, do abastecimento e da distribuição dos alimentos, incluindo-se a água, bem como da geração de emprego e da redistribuição da renda;

II - a conservação da biodiversidade e a utilização sustentável dos recursos;

III - a promoção da saúde, da nutrição e da alimentação da população, incluindo-se grupos populacionais específicos e populações em situação de vulnerabilidade social;

IV - a garantia da qualidade biológica, sanitária, nutricional e tecnológica dos alimentos, bem como seu aproveitamento, estimulando práticas alimentares e estilos de vida saudáveis que respeitem a diversidade étnica e racial e cultural da população;

V - a produção de conhecimento e o acesso à informação; e

VI - a implementação de políticas públicas e estratégias sustentáveis e participativas de produção, comercialização e consumo de alimentos, respeitando-se as múltiplas características culturais do País." BRASIL. Lei $\mathbf{n}^{\circ} 11.346$, de 15 de setembro de 2006. 




nessa concepção de DHAA: a) disponibilidade, que envolve condições de plantio e compra de alimentos; b) adequação, que inclui o aleitamento materno, visa a alimentos livres de substâncias adversas e preocupa-se com seu preparo e consumo; c) acessibilidade, tanto física quanto econômica; e d) estabilidade, que visa garantir o acesso ao alimento de forma regular e permanente. ${ }^{18}$

Desde 2010, com a Emenda Constitucional n 64, a alimentação é considerada um direito social. ${ }^{19} \mathrm{~A}$ inclusão desse direito na Constituição Federal está em consonância com o direito internacional e pode ser considerada uma influência do Pacto Internacional de Direitos Econômicos, Sociais e Culturais (PIDESC), o qual prevê o direito à alimentação desde $1966 .{ }^{20}$ O PIDESC, ao lado do Pacto Internacional dos Direitos Civis e Políticos (PIDCP), veio com a função de suprir uma lacuna da Declaração Universal dos Direitos Humanos (DUDH), que servia apenas de diretriz, sem que pudesse ser exigido seu cumprimento.

No Brasil, tanto o PIDESC quanto o PIDCP foram promulgados em 1992 e passaram a integrar o ordenamento jurídico pátrio. Além de integrarem a legislação nacional, os Pactos são documentos importantes do Sistema Internacional de Proteção dos Direitos Humanos, ou seja, do sistema da

18 VALENTE, Flavio et al. Curso Formação em Direito Humano à Alimentação Adequada. Módulo 1, p. 10-13.

19 "Art. $6^{\circ}$ São direitos sociais a educação, a saúde, a alimentação, o trabalho, a moradia, o lazer, a segurança, a previdência social, a proteção à maternidade e à infância, a assistência aos desamparados, na forma desta Constituição." BRASIL. Constituição (1988). Constituição da República Federativa do Brasil de 1988. Disponível em: <http://www.planalto.gov.br/ ccivil_03/Constituicao/Constituicao.htm> Acesso em: 20 abr. 2015. "ARTIGO 11

1. Os Estados Partes do presente Pacto reconhecem o direito de toda pessoa a um nível de vida adequando para si próprio e sua família, inclusive à alimentação, vestimenta e moradia adequadas, assim como a uma melhoria contínua de suas condições de vida. Os Estados Partes tomarão medidas apropriadas para assegurar a consecução desse direito, reconhecendo, nesse sentido, a importância essencial da cooperação internacional fundada no livre consentimento.

2. Os Estados Partes do presente Pacto, reconhecendo o direito fundamental de toda pessoa de estar protegida contra a fome, adotarão, individualmente e mediante cooperação internacional, as medidas, inclusive programas concretos, que se façam necessárias para:

a) Melhorar os métodos de produção, conservação e distribuição de gêneros alimentícios pela plena utilização dos conhecimentos técnicos e científicos, pela difusão de princípios de educação nutricional e pelo aperfeiçoamento ou reforma dos regimes agrários, de maneira que se assegurem a exploração e a utilização mais eficazes dos recursos naturais;

b) Assegurar uma repartição eqüitativa dos recursos alimentícios mundiais em relação às necessidades, levando-se em conta os problemas tanto dos países importadores quanto dos exportadores de gêneros alimentícios." BRASIL. Decreto $n^{\circ}$ 591, de 6 de julho de 1992. Atos Internacionais. Pacto Internacional sobre Direitos Econômicos, Sociais e Culturais. Promulgação. Disponível em: http://www.planalto.gov.br/ccivil_03/decreto/1990-1994/D0591. htm. Acesso em: 30 jul. 2015. 
Organização das Nações Unidas (ONU) ${ }^{21}$. Assim, na medida em que o Estado não cumpre os direitos por ele assegurados, é possível recorrer ao âmbito internacional com o fim de ter esses direitos respeitados.

Além da previsão constitucional e internacional, o direito à alimentação também está disposto no Programa Nacional de Direitos Humanos (PNDH-3), integrando, portanto, o âmbito das políticas públicas que buscam a efetivação dos direitos humanos. Nesse sentido, existe também, desde 2003, o Conselho Nacional de Segurança Alimentar e Nutricional (CONSEA), que integra a Presidência da República, como órgão de assessoramento imediato à/ao Presidente da República, instituído por meio da Lei $n^{\circ} 10.683$ (Art. $1^{\circ}, \S 1$, III) ${ }^{22}$. Em 2006, foi criado o Sistema Nacional de Segurança Alimentar e Nutricional (SISAN), por meio da referida Lei $n^{\circ}$ 11.346, de 15 de setembro de 2006, com o intuito de assegurar o DHAA. O CONSEA, que passou a integrar o SISAN, foi regulamentado em 2007 por meio do Decreto $n^{\circ}$ 6.272/0723. A agenda da SAN, oriunda do compromisso do Governo Federal como política de Estado, abarca, além de SISAN e CONSEA, a Câmara Intersetorial de Segurança Alimentar e Nutricional (CAISAN) e o Plano Nacional de Segurança Alimentar e Nutricional (PLANSAN 2012/2015). ${ }^{24}$ As Conferências Nacionais de Segurança Alimentar e Nutricional também são importantes instrumentos, possibilitando o diálogo entre sociedade civil e Estado.

Em termos de definição, a alimentação adequada é relacionada, pela doutrina, ao direito ao mínimo existencial e à teoria das necessidades, associada a definições universais e negativas, ou seja, vinculada à ausência de enfermidades a fim de evitar danos. O próprio PIDESC, ao definir a alimentação adequada, conceitua-a negativamente, afirmando não se tratar apenas de calorias, proteínas e outros elementos nutricionais, mas sem propor uma dimensão positiva de como

21 Além do Sistema Internacional (ONU), criado após a Segunda Guerra Mundial, existem os Sistemas Regionais (africano, interamericano e europeu).

22 BRASIL. Lei $\mathbf{n}^{\circ} \mathbf{1 0 . 6 8 3}$, de 28 de maio de 2003. Dispõe sobre a organização da Presidência da República e dos Ministérios, e dá outras providências. Disponível em: <http://www.planalto.gov.br/ccivil_03/leis/2003/L10.683.htm> Acesso em: 1 ago. 2015.

23 BRASIL. Decreto $n^{\circ}$ 6.272, de 23 de novembro de 2007. Dispõe sobre as competências, a composição e o funcionamento do Conselho Nacional de Segurança Alimentar e Nutricional - CONSEA. Disponível em: <http:// www.planalto.gov.br/ccivil_03/_ato2007-2010/2007/Decreto/ D6272.htm> Acesso em: 1 ago. 2015.

24 BRASIL. Ministério do Desenvolvimento Social e Combate à Fome. Disponível em: <http://www.mds.gov.br/ segurancaalimentar/sisan> Acesso em 1. Ago. 2015. 
a alimentação se constitui como "adequada". Essa definição, portanto, deve estar em consonância com o conceito de SAN visto anteriormente.

Embora disposto no PIDESC, o Comentário Geral n 12, sobre o Artigo 11, alargou a definição de alimentação adequada proposta inicialmente:

6. O direito à alimentação adequada realiza-se quando cada homem, mulher e criança, sozinho ou em companhia de outros, tem acesso físico e econômico, ininterruptamente, à alimentação adequada ou aos meios para sua obtenção. O direito à alimentação adequada não deverá, portanto, ser interpretado em um sentido estrito ou restritivo, que o equaciona em termos de um pacote mínimo de calorias, proteínas e outros nutrientes específicos. O direito à alimentação adequada terá de ser resolvido de maneira progressiva. No entanto, os estados têm a obrigação precípua de implementar as ações necessárias para mitigar e aliviar a fome, como estipulado no parágrafo 2 do artigo 11, mesmo em épocas de desastres, naturais ou não. ${ }^{25}$

Conti entende que essa definição, que posteriormente agregou também o acesso à água, está associada diretamente ao direito de se alimentar a partir do seu próprio trabalho, na medida em que as pessoas devem ter o direito de adquirir seus alimentos seguros e saudáveis. ${ }^{26}$ Nesse sentido, o autor afirma que a alimentação é adequada quando for "segura e saudável", mas não desenvolve o que vem a ser o sentido dos adjetivos empregados.

Flávia Piovesan explica que, diferentemente dos direitos civis e políticos, que devem ser assegurados de plano, isto é, que tem autoaplicabilidade, os direitos econômicos, sociais e culturais têm realização progressiva, sendo condicionados à atuação do Estado. ${ }^{27}$ Entretanto, a autora ressalta que existe um minimum core obligation, segundo o qual o núcleo essencial desses direitos precisa ser implementado pelos Estados, disposto na Recomendação Geral n 3. Além de ser progressiva, a aplicação não pode retroceder, ou seja, o núcleo essencial já

25 COMITÊ DESC. Comentário Geral $\mathbf{n}^{0} 12$.

26 CONTI, Irio Luiz. Introdução, p. 8.

27 Artigo $2^{\circ}$, parágrafo $1^{\circ}$ : "Cada um dos Estados Partes no presente Pacto compromete-se a agir, quer com o seu próprio esforço, quer com a assistência e cooperação internacionais, especialmente nos planos econômico e técnico, no máximo dos seus recursos disponíveis, de modo a assegurar progressivamente o pleno exercício dos direitos reconhecidos no presente Pacto por todos os meios apropriados, incluindo em particular por meio de medidas legislativas." ONU. Pacto Internacional dos Direitos Econômicos, Sociais e Culturais. Disponível em: <http://bvsms.saude.gov.br/bvs/publicacoes/pacto_internacional_direitos_ economicos_sociais_culturais. pdf> Acesso em: 20 abr. 2015. 
alcançado não pode retroceder. ${ }^{28}$ Quanto ao conceito, Piovesan também se mantém ao mínimo, imputando ao Estado a erradicação da fome. A autora acrescenta que o mínimo essencial deve ser suficiente, além de nutricionalmente adequado e seguro, a fim de garantir o direito à alimentação adequada e erradicar a fome. ${ }^{29}$

Paulo Cogo Leivas, ao empreender a busca pelo direito ao mínimo existencial e ao direito à alimentação, parte do conceito de necessidade e o vincula a necessidades e satisfações. A teoria das necessidades se distingue entre necessidades básicas e necessidades intermediárias (ou agentes de satisfação das necessidades). As primeiras estão relacionadas à prevenção de prejuízos graves, de modo que estão diretamente associadas ao conceito de dano. "Estar prejudicado gravemente significa estar basicamente incapacitado na busca da visão própria do bem. As necessidades humanas básicas estipulam o que as pessoas precisam alcançar se elas querem evitar prejuízos graves." ${ }^{30}$

Agentes de satisfação universais "são os objetos, atividades e relações que satisfazem as necessidades universalmente, ou seja, em todas as culturas" ${ }^{\prime \prime}$, dentre os quais se encontram alimentos nutritivos e água limpa. Toda ação individual, por sua vez, é condicionada à saúde e à autonomia. O direito ao mínimo existencial, então, é o direito de satisfazer as necessidades básicas. Contudo, como o mínimo existencial depende da saúde e da autonomia, ele se traduz no direito às necessidades intermediárias.

Nas palavras do autor, "quanto ao nível de satisfação de alimentação, saúde, moradia, etc., garantido pelo direito ao mínimo existencial, trata-se da máxima satisfação das necessidades básicas e intermediárias em nível de um ótimo mínimo ou 'minopt'."'32 Leivas afirma que o minopt não deve ser entendido

28 PIOVESAN, Flávia. Proteção dos Direitos Econômicos, Sociais e Cultuais e do Direito à Alimentação Adequada: Mecanismos Nacionais e Internacionais. In: PIOVESAN, Flávia; CONTI, Irio Luiz (Coord.). Direito Humano à Alimentação Adequada. Rio de Janeiro: Lumen Juris, 2007, p. 28-30.

29 PIOVESAN, Flávia. Proteção dos Direitos Econômicos, Sociais e Cultuais e do Direito à Alimentação Adequada: Mecanismos Nacionais e Internacionais, p. 33.

30 LEIVAS, Paulo Cogo. O Direito Fundamental à Alimentação: da Teoria das Necessidades ao Direito ao Mínimo Existencial. In: PIOVESAN, Flávia; CONTI, Irio Luiz (Coord.). Direito Humano à Alimentação Adequada. Rio de Janeiro: Lumen Juris, 2007, p. 80.

31 LEIVAS, Paulo Cogo. O Direito Fundamental à Alimentação: da Teoria das Necessidades ao Direito ao Mínimo Existencial, p. 81.

32 LEIVAS, Paulo Cogo. O Direito Fundamental à Alimentação: da Teoria das Necessidades ao Direito ao Mínimo Existencial, p. 89. 


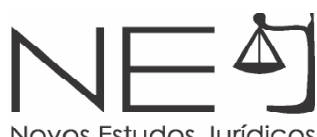

como um nível ínfimo de sobrevivência, ou em termos quantitativos, mas não concede uma definição precisa. ${ }^{33}$ Restringe-se a afirmar que esse padrão deve seguir o padrão de cada sociedade, a fim de que seja realista, distanciando-se de uma abordagem universalizável.

As práticas alimentares saudáveis não podem estar alheias à promoção da saúde. Nesse sentido, o Guia Alimentar para a População Brasileira estabelece "dez passos para uma Alimentação Saudável e Adequada:"

- fazer de alimentos in natura ou minimamente processados a base da alimentação;

- utilizar óleos, gorduras, sal e açúcar em pequenas quantidades ao temperar e cozinhar alimentos e criar preparações culinárias;

- limitar o consumo de alimentos processados;

- evitar o consumo de alimentos ultraprocessados;

- comer com regularidade e atenção, em ambientes apropriados e, sempre que possível, com companhia;

- fazer compras em locais que ofertem variedades de alimentos in natura ou minimamente processados;

- desenvolver, exercitar e partilhar habilidades culinárias;

- planejar o uso do tempo para dar à alimentação o espaço que ela merece;

- dar preferência, quando fora de casa, a locais que servem refeições feitas na hora; e

- ser crítico quanto a informações, orientações e mensagens sobre alimentação veiculadas em propagandas comerciais. ${ }^{34}$

Em certa medida, esses passos refletem o conceito de alimentação adequada adotado pelo Ministério da Saúde, qual seja:

A alimentação adequada e saudável é um direito humano básico que envolve a garantia ao acesso permanente e regular, de forma socialmente justa, a uma prática alimentar adequada aos aspectos biológicos e sociais do indivíduo e que deve estar em acordo com as necessidades

33 LEIVAS, Paulo Cogo. O Direito Fundamental à Alimentação: da Teoria das Necessidades ao Direito ao Mínimo Existencial, p. 82-83.

34 BRASIL. Guia Alimentar para a População Brasileira: instrumento para a promoção da saúde no âmbito do SUS. Disponível em: <http://dab.saude.gov.br/portaldab/guia_alimentar_populacao_brasileira.php> Acesso em: 02 ago. 2015. 
alimentares especiais; ser referenciada pela cultura alimentar e pelas dimensões de gênero, raça e etnia; acessível do ponto de vista de físico e financeiro; harmônica em quantidade e qualidade, atendendo aos princípios da variedade, equilíbrio, moderação e prazer; e baseada em práticas produtivas adequadas e sustentáveis. ${ }^{35}$

Percebe-se que, ao propor uma dimensão positiva, ou seja, de que a alimentação adequada não se trata apenas de elementos nutricionais (tais quais proteínas e calorias), mas se constitui dentro de uma rede de relações sociais que devem envolver a observação acerca da origem dos alimentos, do ambiente e do tempo destinado à realização das refeições e uma perspectiva crítica em relação ao marketing alimentar, a alimentação torna-se parte de uma vida saudável e o indivíduo deve se abster de consumir alimentos industrializados e ultraprocessados, os quais possuem excesso de gorduras, sal e açúcar. Além disso, a produção agroecológica e local é enfatizada, estimulando consumidores a darem preferência para esses alimentos, que atendem também ao aspecto da sazonalidade. O acesso à informação se traduz na rotulagem dos alimentos, fundamental para que se possam fazer essas escolhas. Nesse sentido, inclui-se especialmente os organismos geneticamente modificados (OGMs) que, embora tenham sua produção liberada no Brasil, violam o princípio da precaução.

Como se pode inferir da noção de alimentação saudável e adequada incentivada pela legislação e pelo Guia Alimentar, o ato de se alimentar possui também implicações políticas. Por isso, é relevante compreender também alguns aspectos vinculadas às escolhas de consumo e à formação da ideia do consumidor verde e sustentável, a fim de identificar como e por que as pessoas fazem escolhas alimentares em direção à alimentação saudável.

\section{ALIMENTO SUSTENTÁVEL E CONSUMIDOR VERDE}

No esforço para definir o que são alimentos sustentáveis, Peter Oosterveer, Julia S. Guivant e Gert Spaargaren explicam que é necessário aplicar uma definição sociológica do alimento sustentável, e não meramente técnica. Com base nisso, afirmam que:

35 BRASIL. Guia alimentar para a população brasileira. 2. ed. Brasília: Ministério da Saúde, 2014 , p. 8. 
Em lugar de assumir uma ótica normativa com respeito à produção e consumo de alimentos sustentáveis em diferentes países e entre diferentes grupos de consumidores preferimos conceber o consumo verde como uma categoria multidimensional, cobrindo diferentes "preocupações dos consumidores" sobre alimentos, todas elas incluindo alimentos sustentáveis, mas com diferente importância. ${ }^{36}$

Assim, identificam quatro dimensões que não são mutuamente exclusivas: naturalidade, segurança alimentar, bem-estar animal e preocupações ambientais. A naturalidade se refere a alimentos não adulterados e produzidos por meio de processos naturais. Exemplos desse tipo são os alimentos orgânicos e os integrais, livres de ingredientes artificiais e conservantes. A procura por alimentos naturais é relacionada à nutrição, à melhora da saúde e à qualidade do alimento. A preocupação com a segurança alimentar tem origem nas crises alimentares, como a doença da vaca louca, os OGM's e a gripe aviária, por exemplo. O bem-estar animal traduz a preocupação dos consumidores sobre o método de produção bioindustrializado, especialmente de ovos e frangos, trazido à tona pelos defensores do bem-estar animal, os quais se contrapõem à produção no formato industrial de larga escala desses alimentos. As preocupações ambientais (ou com os ecossistemas), por fim, são destacadas pelas organizações ambientalistas e pelos movimentos sociais, que questionam a produção moderna e o consumo de alimentos industriais. Segundo eles, a produção e o consumo de alimentos devem ser sustentáveis, conforme a definição do relatório Brundtland, isto é, às futuras gerações precisa ser resguardado o direito de sustentar a vida humana nas mesmas condições. ${ }^{37}$

Ao analisar o consumidor de alimentos sustentáveis, Oosterveer, Guivant e Spaargaren lembram que as pesquisas acadêmicas e de mercado tendem a classificálo, especialmente os consumidores de orgânicos, como um segmento uniforme da população. Entretanto, tais autores criticam essa perspectiva demonstrando que as respostas dos consumidores nas pesquisas e suas práticas diárias não são necessariamente correspondentes. Os autores afirmam que as escolhas individuais deveriam fazer parte de um contexto mais amplo, razão pela qual as mudanças no

36 OOSTERVEER, Peter; GUIVANT, Julia S.; SPAARGAREN, Gert. Alimentos verdes em supermercados globalizados: uma agenda teórico-metodológica. In: GUIVANT, Julia S.; SPAARGAREN, Gert; RIAL, Carmen (org.) Novas práticas alimentares no mercado global. Florianópolis: UFSC, 2010, p. 25.

37 OOSTERVEER, Peter; GUIVANT, Julia S.; SPAARGAREN, Gert. Alimentos verdes em supermercados globalizados: uma agenda teórico-metodológica, p. 25-26. 
seu comportamento também deveriam ser associadas a mudanças mais amplas na sociedade, e não restritas a mecanismos psicológicos (atitudinais). ${ }^{38}$

Dentre as razões pelas quais consumidores optam por alimentos sustentáveis, os autores citam as preocupações relacionadas ao ambiente, à segurança alimentar e à saúde, bem como os estilos de vida e a confiança do consumidor nos alimentos. ${ }^{39}$ Todavia, essas opções podem estar combinadas, isto é, a busca pela segurança alimentar e saúde pode incorporar diferentes estilos de vida. Oosterveer, Guivant e Spaargaren citam um estudo de marketing da Biohandel na Alemanha, no qual foram distinguidas três categorias de consumidores interessados em alimentos orgânicos:

a) pós-materialistas: preferem orgânicos em função do ambiente, assim como por prazer, paladar, bem-estar e saúde. A rotulagem e a certificação garantem a compra certa;

b) consumidores de classe média: veem orgânicos com uma tendência e optam por status. Importam-se com alimentos livre de químicos e pesticidas, conquanto não tenham conhecimento aprofundando;

c) performers modernos: associam orgânicos à boa forma e à energia. Conhecem pouco sobre orgânicos e não valoram rótulos e categorizações. ${ }^{40}$

Os autores explicam que essas categorias refletem a individualização das preferências culinárias, ou seja, elas se vinculam a diferentes faixas etárias, destacando-se crianças e adolescentes, bem como a restrições dietéticas, atribuídas a sensibilidades alimentares, alergias e diferentes formas de vegetarianismo.

Ainda sobre o consumidor, é trazida à tona pelos autores a relação ambígua entre confiança e risco nos sistemas alimentares. Eles concluem que os mecanismos tradicionais geradores de confiança não serão efetivos nos circuitos globais de provisão de alimentos, eis que o contato com o produtor no mercado local e visitas aos locais nos quais os alimentos são produzidos não são meios relevantes e dominantes para gerar a confiança do consumidor. Defendem que as

38 OOSTERVEER, Peter; GUIVANT, Julia S.; SPAARGAREN, Gert. Alimentos verdes em supermercados globalizados: uma agenda teórico-metodológica, p. 21-22.

39 OOSTERVEER, Peter; GUIVANT, Julia S.; SPAARGAREN, Gert. Alimentos verdes em supermercados globalizados: uma agenda teórico-metodológica, p. 36.

40 OOSTERVEER, Peter; GUIVANT, Julia S.; SPAARGAREN, Gert. Alimentos verdes em supermercados globalizados: uma agenda teórico-metodológica, p. 36-37. 
ferramentas geradoras de confiança são os sistemas abstratos, a perícia científica e os sistemas de informações, segundo os quais consumidores podem avaliar a qualidade dos alimentos à longa distância, confiando em tais informações. Esses novos sistemas incluem profissões médicas, serviços de saúde, organismos estatais, assistência social, dentre outros. ${ }^{41}$

Salienta-se que a confiança no sistema alimentar não se limita aos produtos e às tecnologias, pois abrange também as pessoas que trabalham nas cadeias alimentares. Em virtude da impossibilidade de manter uma relação pessoal com o produtor, o consumidor confia nos alimentos sustentáveis comprados em estabelecimentos varejistas com características específicas. A confiança é estabelecida por meio da imagem ambiental da companhia e da presença ativa, por meio dos rótulos das certificadoras. ${ }^{42}$

Entretanto, ainda que os autores defendam esses sistemas, apontam seus limites, a partir das análises de Beck et al. e Giddens, os quais consideram que a confiança em sistema abstrato é: a) frágil e precisa ser constantemente monitorada, visto que as pessoas têm consciência que um sistema pode deixar de ser seguro quando afetado por um crise alimentar; b) relacionada aos sistemas de compra e produção e seus princípios organizacionais, assim como às pessoas que possibilitam o funcionamento desses sistemas; c) reproduzida/perturbada/restabelecida nos "pontos de acesso", cujos leigos encontram os peritos dos sistemas. ${ }^{43}$ Desse modo, os autores atestam que há dois meios condutores do crescimento considerável no consumo de alimentos sustentáveis, em escala mundial: 1) a consciência da necessidade de fazer escolhas diárias no consumo de alimentos; e 2) a presença de incertezas e ambiguidades ao confiar em produtos alimentares. ${ }^{44}$ Percebe-se que a escolha do consumidor é importante e reflete seu posicionamento em relação ao modo de produção dos alimentos. Embora diferentes motivos possam orientar essas escolhas, serão vistos adiante os aspectos éticos que norteiam as preocupações alimentares.

41 OOSTERVEER, Peter; GUIVANT, Julia S.; SPAARGAREN, Gert. Alimentos verdes em supermercados globalizados: uma agenda teórico-metodológica, p. 23.

42 OOSTERVEER, Peter; GUIVANT, Julia S.; SPAARGAREN, Gert. Alimentos verdes em supermercados globalizados: uma agenda teórico-metodológica, p. 39.

43 OOSTERVEER, Peter; GUIVANT, Julia S.; SPAARGAREN, Gert. Alimentos verdes em supermercados globalizados: uma agenda teórico-metodológica, p. 23.

44 OOSTERVEER, Peter; GUIVANT, Julia S.; SPAARGAREN, Gert. Alimentos verdes em supermercados globalizados: uma agenda teórico-metodológica, p. 23. 


\section{ASPECTOS ÉTICOS DA ALIMENTAÇÃO}

Nas sociedades democráticas, os cidadãos têm liberdade para realizarem suas escolhas alimentares. É da responsabilidade de cada sujeito autônomo determinar o curso de alimentação que pretende seguir. Em grande medida, as escolhas alimentares são constituídas pelos costumes e pelas práticas familiares e locais, bem como pela tradição religiosa à qual o sujeito pertence. Não cabe ao Estado interferir nessa liberdade e determinar as escolhas do que se deve e o que não se deve comer. Todavia, é função do Estado disponibilizar e informar as pessoas acerca das consequências de suas escolhas em termos de alimentação e incentivar práticas que mantenham o organismo saudável. Ao mesmo tempo, é direito do ser humano ser informado sobre os ingredientes que compõem os alimentos consumidos e ter à sua disposição alimentos de qualidade biológica, sanitária e nutricional.

A interferência do Estado na questão da alimentação pode se dar apenas por meio da garantia do direito à alimentação e à segurança alimentar, conforme destacado anteriormente pormeio da LOSAN. Tal lei não define que tipo de alimentos devem ser ingeridos para uma alimentação adequada, apenas indica, em seu artigo primeiro, que o poder público, juntamente com a participação da sociedade civil organizada, pode formular e implementar políticas, planos, programas e ações tendo em vista assegurar o DHAA. Prevê ainda, em seu artigo $4^{\circ}$, IV, o estímulo de "práticas alimentares e estilos de vida saudáveis que respeitem a diversidade étnica e racial e cultural da população" 45 . Nesse sentido, a legislação indica, de fato, uma vinculação entre a alimentação adequada e a alimentação promotora da saúde. Mais recentemente, o também referido Guia Alimentar para a População Brasileira reflete claramente esse entendimento, ao dispor de um conjunto de informações e recomendações que tem por finalidade promover a saúde alimentar. O Guia não se limita à geração atual, mas objetiva motivar hábitos alimentares saudáveis cujas consequências se estendam para as gerações futuras, mostrando de certo modo um comprometimento moral com a saúde daqueles que ainda virão a nascer. $A$ construção de hábitos alimentares adequados na atualidade trará consequências positivas para além da geração presente.

$45 \quad$ BRASIL. Lei $\mathrm{n}^{\circ}$ 11.346, de 15 de setembro de 2006. 
O Guia vai além da legislação ao fazer recomendações no sentido de preferir alimentos in natura ou minimamente processados em detrimento de produtos disponibilizados no mercado consumidor. Com isso, a configuração da expressão "alimentação adequada" ganha contornos cada vez mais claros. A preocupação com a conduta alimentar fica evidenciada seja no uso de termos como "guia" e "princípios", seja nas orientações mais diretas apresentadas no segundo capítulo da obra que aponta para uma alimentação "nutricionalmente balanceada, saborosa, culturalmente apropriada e promotora de um sistema alimentar socialmente e ambientalmente sustentável", cuja base seja a grande variedade de alimentos de origem vegetal. ${ }^{46}$ Considerando esse posicionamento, o Guia caminha em conformidade com a reformulação da tradicional "pirâmide" alimentar de Harvard, que, em sua última versão, direciona-se fortemente para a valorização de uma dieta baseada em plantas (vegetais, sementes, grãos integrais, frutas, feijões e castanhas). ${ }^{47}$

Nesse contexto, é importante considerar que a própria construção da pirâmide alimentar formada por quatro grupos (leite, carne, frutas/vegetais e pães/cereais) surge, nos Estados Unidos, somente em 1956, por influência da indústria de carnes e laticínios. Entretanto, Carol J. Adams afirma que essa situação demonstra como uma questão de produção se torna uma consideração nutricional. A justificativa para a inclusão da carne e dos laticínios é de que eles teriam proteínas, vitaminas e minerais, ao passo que os interesses econômicos da indústria estavam de fato orientando a mudança na pirâmide, em detrimento da saúde dos consumidores que passaram a ficar mais vulneráveis ao risco de câncer, doenças cardíacas, obesidade, diabetes e osteoporose, associados ao consumo de gordura e proteína animal. ${ }^{48}$

Conforme salientado no item anterior, é crescente o número de indivíduos preocupados com o aspecto nutricional e político da alimentação, buscando alternativas não apenas mais saudáveis, mas também sustentáveis, à produção de alimentos em escala industrial pelo agronegócio e pelas multinacionais do setor alimentício. A reivindicação da soberania alimentar, isto é, o direito de "produzir,

$46 \quad$ BRASIL. Guia alimentar para a população brasileira, p. 26.

47 HARVARD UNIVERSITY. Food Pyramids and Plates: What Should You Really Eat? Disponível em: <http://www. hsph.harvard.edu/nutritionsource/pyramid-full-story/> Acesso em: 8 ago. 2015.

48 ADAMS, Carol J. Neither Man nor Beast: Feminism and the Defense of Animals. New York: Continuum, 1995, p. 33-34. 
transformar, consumir, importar e exportar alimentos sem reproduzir modelos que gerem injustiça social, de forma sustentável, conservando e resgatando a diversidade produtiva e cultural de um povo"49, é igualmente reflexo dessa forma política de pensar a alimentação. É esse tipo de posicionamento que permite, por exemplo, o desenvolvimento de condutas como a dos consumidores verdes.

O Guia Alimentar para a População Brasileira também apresenta uma perspectiva crítica em relação a certos modos de produção que priorizam produtividade massificada de alimentos na forma de monoculturas, sem a preocupação com a qualidade e a sustentabilidade. Ao contrário, o Guia procura reconhecer a importância de promover sistemas alimentares socialmente e ambientalmente sustentáveis:

Recentemente, na maior parte do mundo, as formas de produzir e distribuir alimentos vêm se modificando de forma desfavorável para a distribuição social das riquezas, assim como para a autonomia dos agricultores, a geração de oportunidades de trabalho e renda, a proteção dos recursos naturais e da biodiversidade e a produção de alimentos seguros e saudáveis. Estão perdendo força sistemas alimentares centrados na agricultura familiar, em técnicas tradicionais e eficazes de cultivo e manejo do solo, no uso intenso de mão de obra, no cultivo consorciado de vários alimentos combinado à criação de animais, no processamento mínimo dos alimentos realizado pelos próprios agricultores ou por indústrias locais e em uma rede de distribuição de grande capilaridade integrada por mercados, feiras e pequenos comerciantes. No lugar, surgem sistemas alimentares que operam baseados em monoculturas que fornecem matérias-primas para a produção de alimentos ultraprocessados ou para rações usadas na criação intensiva de animais. Esses sistemas dependem de grandes extensões de terra, do uso intenso de mecanização, do alto consumo de água e de combustíveis, do emprego de fertilizantes químicos, sementes transgênicas, agrotóxicos e antibióticos e, ainda, do transporte por longas distâncias. Completam esses sistemas alimentares grandes redes de distribuição com forte poder de negociação de preços em relação a fornecedores e consumidores finais. ${ }^{50}$

Diante de tais problemas, o Guia visa constituir-se em recurso para a ampliação da autonomia nas escolhas alimentares, dando privilégio a alimentos cujo "sistema de produção e distribuição seja socialmente e ambientalmente

49 VALENTE, Flavio et al. Curso Formação em Direito Humano à Alimentação Adequada. Módulo 7, p. 9.

50 BRASIL. Guia alimentar para a população brasileira, p. 19-20. 
sustentável", para que indivíduos se tornem cada vez mais conscientes acerca das implicações para si e para os demais que derivam daquilo que escolhem consumir. Uma vez que se tem acesso a informações, ainda que prevaleça o problema mencionado anteriormente, das incertezas e das ambiguidades ao confiar em produtos alimentares, as escolhas tornam-se mais bem informadas e permitem que pessoas, famílias e comunidade "exijam o cumprimento do direito humano à alimentação adequada e saudável". ${ }^{51}$ Como se pode observar, emerge uma dimensão ética do problema da alimentação à medida que escolhas alimentares podem promover, ou não, o bem da vida de outras pessoas envolvidas na produção de alimentos.

Em muitas situações, a politização do ato de se nutrir aparece vinculada a uma preocupação ética com a origem e a qualidade daquilo que se ingere. Se o cidadão tem a liberdade da escolha, também busca, muitas vezes, tomar decisões responsáveis e informadas, reconhecendo que se alimentar é também uma questão de implicações éticas. $O$ ato de comer não é um ato isolado, sem consequências para além do próprio organismo que ingere os alimentos.

Há uma rede complexa de relações envolvida na produção de determinado alimento que não está referida dentro de uma concepção estrita de desenvolvimento econômico ${ }^{52}$. Por isso, possui também implicações éticas que se refletem em questões do tipo: há exploração humana por trás dos alimentos consumidos? Quem obtém a maior parte dos lucros com a produção de alimentos? Ao se pensar mais além e adotar o paradigma não especista e não antropocêntrico, pode-se ainda questionar: há exploração de animais não humanos por trás dos alimentos consumidos? A quem se restringe o direito à autodeterminação alimentar e à alimentação saudável? Essa última questão

51 BRASIL. Guia alimentar para a população brasileira, p. 21.

52 Dower elenca três dificuldades centrais ao se pensar o desenvolvimento estritamente em termos de crescimento econômico. Em primeiro lugar, crescimento como tal não necessariamente beneficia os pobres, ao contrário, pode até prejudicá-los, como tem acontecido com o agronegócio que acaba por simplesmente excluir pequenos agricultores do processo de produção. Em segundo lugar, há o perigo de prevalecer um modelo ocidental de crescimento econômico, cuja implementação e mudanças consequentes são partes de uma economia global a ser dominada pelo ocidente. Em terceiro lugar, mesmo projetando um modelo de crescimento econômico que priorize o crescimento para os pobres, isto é, cujas consequências de crescimento afetem positivamente a condição dos pobres, é necessário que outras considerações sejam realizadas. O crescimento econômico não pode ser descontextualizado, mas precisa ser pensado em meio a restrições ambientais como a poluição e a degradação da terra (DOWER, Nigel. World poverty. In. SINGER, Peter (Org.). A Companion to Ethics. Oxford: Blackwell, 1993, p. 273-283, p. 275). 
Novos Estudos Jurídicos

permite pensar a questão da alimentação de animais domesticados, seja os de companhia, seja os explorados para servir aos seres humanos, os quais, via de regra, não têm à disposição a autonomia prática para autodeterminar seu curso alimentício. A preocupação com uma alimentação adequada não tem ocupado muito espaço no campo da ética. As reflexões nesse campo aparecem comumente associadas às questões de pobreza e de ampliação da comunidade moral para além de seres humanos, incluindo animais e meio ambiente. No que concerne à pobreza, as discussões enfocam a extensão da obrigação de ajudar aos outros, garantindo, primordialmente, a eliminação da pobreza extrema, o que está vinculado à possibilidade de uma vida digna e longa, sem dor e sofrimento resultante de fome e doenças a ela associadas, mantendo, com isso, um mínimo de dignidade e decência na vida ${ }^{53}$. A redução da pobreza implica necessariamente garantir certo padrão mínimo de alimentação para a sobrevivência digna, ainda que aqui não sejam feitas considerações voltadas especificamente para a questão da "adequação" dessa alimentação.

No que toca ao tema da expansão da comunidade moral, merecem destaque as considerações de Peter Singer que, ao tratar da inclusão da vida de animais sencientes nas nossas ponderações morais, chama a atenção para o fato de que uma alimentação "adequada" é aquela que reduz as possibilidades de causar dor e sofrimento, isto é, de interferir no interesse de outro ser senciente em levar uma vida que lhe seja agradável e tanto quanto possível ausente de dor e sofrimento. O argumento central de Singer é que "se um ser sofre, não pode haver nenhuma justificativa de ordem moral para nos recusarmos a levar esse sofrimento em consideração". ${ }^{54}$ Independentemente da espécie desse ser, o princípio de igualdade de interesses semelhantes, proposto por Singer como a base para a sua concepção ética, "exige que o sofrimento seja levado em conta em termos de igualdade com o sofrimento semelhante - até onde podemos fazer comparações aproximadas - de qualquer outro ser". ${ }^{55}$

53 DOWER, Nigel. World poverty, p. 277.

54 SINGER, Peter. Ética prática. 3. ed. São Paulo: Martins Fontes, 2002, p. 67.

55 SINGER, Peter. Ética prática, p. 67. 
No entender de Singer, portanto, uma alimentação humana que não preserva o bem da vida individual de seres sencientes não humanos, representados mormente pelo seu interesse em ter uma vida que lhes seja agradável, não pode se constituir em uma alimentação adequada. É um modelo alimentar que se constrói diretamente sobre a exploração de outras vidas, humanas e não humanas. Conforme destaca Paul W. Taylor, cada vida individual possui um "bem que lhe é próprio", constitui-se como um centro teleológico de vida com um modo singular de se realizar que necessita ser preservado e que tenha espaço para florescer do modo que é próprio a sua espécie. ${ }^{56}$ Singer aponta ser injustificável a criação de animais em fazendas industriais dada a quantidade de sofrimento gerada para cada um dos animais que tem sua vida prematura submetida a esse processo de mera objetificação para satisfazer interesses gustativos humanos. ${ }^{57}$ Ademais, tal sistema produtivo de animais para fins de alimentação humana exige a produção de grande quantidade de cereais, levando à expansão da monocultura, os quais são transformados em ração para gerar produtos de origem animal, muitos dos quais são alimentos amplamente processados. Nesse sentido, além da perda direta da vida animal senciente e valiosa em si mesma, há uma limitação indireta que caracteriza esse sistema produtivo, uma vez que gera desperdício de recursos e acelera a destruição ambiental. Como bem pontua Singer, "se parássemos de alimentar os animais com grãos e com soja, a quantidade de alimentos poupado seria - caso fosse distribuído aos que dele necessitam - mais do que suficiente para acabar com a fome no mundo inteiro". ${ }^{58}$

Uma consciência alimentar informada leva o sujeito, muitas vezes, a se perguntar sobre os efeitos de suas ações rotineiras; leva-o a se questionar, conforme exemplifica Gruen, sobre "quem são esses animais que sofrem e morrem para que eu possa comer carne assada?". ${ }^{59}$ A informação pode tornar os sujeitos mais sensibilizados diante das práticas de crueldade e sofrimento envolvidos na produção desses alimentos que, geralmente, em nada contribuem

56 TAYLOR, Paul W. Respect for Nature: A Theory of Environmental Ethics. Princeton: Princeton University Press, 1986, p. 76-77.

57 SINGER, Peter. Ética prática, p. 142.

58 SINGER, Peter. Ética prática, p. 231-232.

59 GRUEN, Lori. Animals. In: SINGER, Peter (Org.). A Companion to Ethics. Oxford: Blackwell, 1993, p. 343-353, p. 351. 
para a saúde humana. Ao contrário, o consumo desses alimentos animalizados tem consequências negativas para o organismo humano e contribui para o desenvolvimento de uma série de doenças. Não são, deste modo, alimentos seguros e saudáveis. Mas a maior parte das pessoas está protegida de saber as consequências de suas ações. Em geral, pessoas são mantidas distantes do modo de funcionamento do modelo de produção em confinamento desses animais, sendo que a carne que consomem configura o que Carol J. Adams denomina de "referente ausente". Ao serem oferecidos para consumo em pedaços, os animais tornam-se referentes ausentes, isto é, o termo "carne" separa o agora alimento do nome do animal e do corpo que o constitui. Nas palavras de Adams: "animais em nome e corpo são tornados ausentes enquanto animais para que a carne exista. As vidas dos animais precedem e tornam possíveis a existência da carne. Se animais estão vivos, eles não podem ser carne. Assim, um corpo morto substitui o animal vivo". ${ }^{60}$ Por meio desse processo de transformação de animais em comida, com o auxílio da linguagem, os consumidores de corpos animais terminam, em geral, por não associar o pedaço de corpo ao animal que lhe deu origem ao morrer. Isso permite afirmar uma certa falta de autonomia do sujeito para decidir de forma consciente e informada sobre a alimentação adequada.

Quando indivíduos passam a conhecer que o modo como se alimentam leva muitos animais a terem uma vida curta de privações, sem movimento e sem conforto, ou mesmo qualquer noção de bem-estar de acordo com a qualidade de vida de sua espécie; quando sabem que seus hábitos conduzem à morte prematura milhões de animais afastados da convivência de outros da mesma espécie, é possível uma crescente consciência acerca de uma ampliação do sentido da própria noção de alimentação adequada. Segundo Gruen, "a simpatia que as pessoas podem naturalmente sentir em relação a um ser que está sofrendo, acoplada a princípios morais fundamentados, provavelmente levaria muitos a se oporem a essas instituições". ${ }^{61}$ Nesse sentido, a defesa de uma alimentação adequada pode conduzir a um comprometimento ético com todos aqueles envolvidos na produção de alimentos, incluindo os animais não humanos explorados nesse processo sem que sua autonomia prática de viver em liberdade, de mover-se para prover-se, seja levada em consideração.

60 ADAMS, Carol J. The Sexual Politics of Meat: A Feminist-Vegetarian Critical Theory. 20 ed. New York: Continuum, 2011, p. 66.

61 GRUEN, Lori. Animals, p. 351. 
A Lei $n^{\circ}$ 11.346, de 15 de setembro de 2006, tratou de efetivar o direito humano fundamental à alimentação no Brasil, reconhecido no texto constitucional de 1988 e inerente à dignidade da pessoa humana, associando-o não meramente a uma quantidade suficiente de alimentos, mas também às noções de segurança alimentar e nutricional, à saúde e às práticas alimentares que preservem a diversidade cultural e ambiental nacional. Embora reconheça a importância de práticas alimentares sustentáveis, a legislação não dá conteúdo positivo a uma noção de "alimentação adequada" que aparece em seu texto. Essa dimensão positiva passa a ser estabelecida no Guia Alimentar da População Brasileira.

Ao relacionar o direito humano à alimentação adequada com a erradicação da fome, denota-se uma dimensão política da questão, a saber, de que a fome é muito mais um problema de distribuição e de desperdício de alimentos do que de insuficiência de produção. A alimentação adequada reflete, portanto, sobre o próprio modo como alimentos são produzidos, isto é, que processos e procedimentos estão envolvidos na produção de determinados alimentos, indo além de meras considerações acerca de quantidades adequadas de calorias e proteínas a serem ingeridas diariamente. Em primeiro lugar, isso aponta para uma vinculação entre alimentação e promoção da saúde. Em segundo lugar, para uma ligação entre alimentação e sustentabilidade. E, por fim, em terceiro lugar, leva para uma perspectiva ética do problema da alimentação, segundo a qual considerações éticas também são fundamentais para definir o que constitui uma alimentação saudável e segura ou, dito de outro modo, uma alimentação adequada.

A partir do que se estabelece no Guia Alimentar da População Brasileira, de considerações acerca do consumidor verde que busca o alimento sustentável e de uma fundamentação ética a partir de um viés não antropocêntrico, procurouse delimitar de forma positiva o que é uma alimentação adequada. Ao se adotar o raciocínio ético de Peter Singer, tem-se que uma alimentação adequada será aquela que não apenas melhor atender aos interesses e às preferências do sujeito em busca de alimento, mas também levar em conta os interesses e as preferências dos demais afetados pela ação de se nutrir, sejam interesses de outros seres humanos 
Novos Estudos Jurídicos

envolvidos no processo de produção de alimentos, sejam de animais sencientes transformados em meros objetos na cadeia produtiva. Em outros termos, sob essa perspectiva de entendimento, a alimentação adequada não se dá desvinculada da preservação do bem que é próprio a outras formas de vida. A partir disso, tem-se que é fundamental o acesso à informação para que os indivíduos possam realizar escolhas conscientes de autodeterminação alimentar e nutricional.

\section{REFERÊNCIAS DAS FONTES CITADAS}

ADAMS, Carol J. Neither Man nor Beast: Feminism and the Defense of Animals. New York: Continuum, 1995.

The Sexual Politics of Meat: A Feminist-Vegetarian Critical Theory. 20 ed. New York: Continuum, 2011.

BRASIL. Constituição (1988). Constituição da República Federativa do Brasil de 1988. Disponível em: <http://www.planalto.gov.br/ccivil_03/ Constituicao/Constituicao. htm> Acesso em: 20 abr. 2015.

Decreto $n^{\circ}$ 591, de 6 de julho de 1992. Atos Internacionais. Pacto Internacional sobre Direitos Econômicos, Sociais e Culturais. Promulgação. Disponível em: <http://www. planalto.gov.br/ccivil_03/decreto/1990-1994/D0591.htm> Acesso em: 30 jul. 2015.

Decreto $n^{\circ}$ 6.272, de 23 de novembro de 2007. Dispõe sobre as competências, a composição e o funcionamento do Conselho Nacional de Segurança Alimentar e Nutricional - CONSEA. Disponível em: <http://www.planalto.gov.br/ccivil_03/_ato20072010/2007/Decreto/D6272.htm> Acesso em: 1 ago. 2015.

2014.

Guia Alimentar para a População Brasileira. 2. ed. Brasília: Ministério da Saúde,

Guia Alimentar para a População Brasileira: instrumento para a promoção da saúde no âmbito do SUS. $2^{\text {a }}$ ed. Brasília, DF: Ministério da Saúde, 2014. Disponível em: <http:// dab.saude.gov.br/portaldab/guia_alimentar_populacao_brasileira.php> Acesso em: 02 ago. 2015.

Lei $\mathbf{n}^{\circ} \mathbf{1 0 . 6 8 3}$, de 28 de maio de 2003. Dispõe sobre a organização da Presidência da República e dos Ministérios, e dá outras providências. Disponível em: <http://www.planalto. gov.br/ccivil_03/leis/2003/L10.683.htm> Acesso em: 1 ago. 2015.

Lei n $^{\circ}$ 11.346, de 15 de setembro de 2006. Cria o Sistema Nacional de Segurança Alimentar e Nutricional - SISAN com vistas em assegurar o direito humano à alimentação adequada e dá outras providências. Disponível em: <http://www.planalto.gov.br/ccivil_03/_ ato2004-2006/2006/lei/l11346.htm> Acesso em: 31 jul. 2015. 
. Ministério do Desenvolvimento Social e Combate à Fome. Disponível em: <http:// www.mds.gov.br/segurancaalimentar/sisan> Acesso em 1. Ago. 2015.

COMITÊ DESC. Comentário Geral n 12. Disponível em: < http://pfdc.pgr.mpf.mp.br/atuacaoe-conteudos-de-apoio/publicacoes/ alimentacao-adequada/Comentario\%20Geral\%20 No\%2012.pdf> Acesso em: 20 abr. 2015.

CONTI, Irio Luiz. Introdução. In: PIOVESAN, Flávia; CONTI, Irio Luiz (Coord.). Direito Humano à Alimentação Adequada. Rio de Janeiro: Lumen Juris, 2007, p. 1-13.

DOWER, Nigel. World poverty. In: SINGER, Peter (Org.). A Companion to Ethics. Oxford: Blackwell, 1993, p. 273-283.

FAO, IFAD and WFP. The State of Food Insecurity in the World 2014. Strengthening the enabling environment for food security and nutrition. Rome, FAO, 2014.

GIL, Antônio Carlos. Métodos e técnicas de pesquisa social. 5. ed. São Paulo: Atlas, 2007. GRUEN, Lori. Animals. In: SINGER, Peter (Org.). A Companion to Ethics. Oxford: Blackwell, 1993, p. 343-353.

HARVARD UNIVERSITY. Food Pyramids and Plates: What Should You Really Eat? Disponível em: < http://www.hsph.harvard.edu/nutritionsource/ pyramid-full-story/> Acesso em: 8 ago. 2015.

ONU. Pacto Internacional dos Direitos Econômicos, Sociais e Culturais. Disponível em: <http://bvsms.saude.gov.br/bvs/publicacoes/pacto_internacional_direitos_economicos_ sociais_culturais.pdf> Acesso em: 20 abr. 2015.

OOSTERVEER, Peter; GUIVANT, Julia S.; SPAARGAREN, Gert. Alimentos verdes em supermercados globalizados: uma agenda teórico-metodológica. In: GUIVANT, Julia S.; SPAARGAREN, Gert; RIAL, Carmen (org.) Novas práticas alimentares no mercado global. Florianópolis: UFSC, 2010, p. 15-57.

PIOVESAN, Flávia. Proteção dos Direitos Econômicos, Sociais e Cultuais e do Direito à Alimentação Adequada: Mecanismos Nacionais e Internacionais. In: PIOVESAN, Flávia; CONTI, Irio Luiz (Coord.). Direito Humano à Alimentação Adequada. Rio de Janeiro: Lumen Juris, 2007, p. 17-48.

SINGER, Peter. Ética prática. 3. ed. São Paulo: Martins Fontes, 2002.

TAYLOR, Paul W. Respect for Nature: A Theory of Environmental Ethics. Princeton: Princeton University Press, 1986.

VALENTE, Flavio et al. Curso Formação em Direito Humano à Alimentação Adequada. Módulo 1. ABRANDH, 2007. 
Novos Estudos Jurídicos

Curso Formação em Direito Humano à Alimentação Adequada. Módulo 7. ABRANDH, 2007.

ZIEGLER, Jean. Prefácio. In: PIOVESAN, Flávia; CONTI, Irio Luiz (Coord.). Direito Humano à Alimentação Adequada. Rio de Janeiro: Lumen Juris, 2007, p. ix-xi.

Recebido em: 02/04/2018

Aprovado em: 22/04/2019 